\title{
RESISTÊNCIA DA MADEIRA DE QUATRO ESSÊNCIAS UTILIZADAS NA ARBORIZAÇÃO URBANA A Coptotermes gestroi (WASMANN, 1896)
}

\author{
Felipe Marauê Marques Tieppo ${ }^{1}$, Henrique Trevisan², Acacio Geraldo de Carvalho ${ }^{3}$.
}

\section{RESUMO}

Os cupins são insetos sociais da ordem Isoptera, que contém cerca de 2750 espécies descritas no mundo. São conhecidos por sua importância econômica como pragas de madeira e de outros materiais celulósicos. O presente trabalho teve como objetivo avaliar a resistência da madeira de quatro espécies florestais, muito utilizadas na arborização urbana, ao ataque de $C$. gestroi. As madeiras utilizadas para a realização do experimental foram coletadas no campus da Universidade Federal Rural do Rio de Janeiro. Foi utilizada, para o ensaio, uma câmara de alvenaria, onde térmitas da espécie C. gestroi ocorriam naturalmente. Amostras de madeiras, medindo 6 a $8 \mathrm{~cm}$ de diâmetro e $5 \mathrm{~cm}$ de altura foram dispostas em cinco repetições nos cinco blocos, dentro da mesma. Após trinta dias as amostras foram retiradas da estrutura, sendo analisadas em seguida. Foi encontrado um total de 220 insetos. A espécie que mais sofreu ataque foi $P$. aquatica (46) e a que menos sofreu ataque foi $I$. marginata (0). A espécie $I$. marginata é indicada para áreas onde a ocorrência de cupins é alta, já $P$. aquática não é indicado para áreas infestadas. A densidade não e um fator que confere resistência aos térmitas, sendo atribuído à concentração de extrativos tóxicos, essa função.

Palavras chave: Madeira, Durabilidade, Térmitas

1. Aluno de graduação em Engenharia Floresta, UFRRJ, Seropédica-RJ, marauetieppo@yahoo.com.br

2. Doutorando em ciências Ambientais e Florestais, UFRRJ, Seropédica-RJ, hentrevisan@gmail.com

3. Professor Associado I, Departamentos de Produtos Florestais, UFRRJ, Seropédica-RJ, acacio@ufrri.br 


\title{
RESISTANCE THE WOOD OF FOUR ESSENCES USED IN URBAN ARBORIZATION THE Coptotermes gestroi (WASMANN, 1896)
}

\begin{abstract}
The termites are social insects of the order Isoptera, that contains about 2750 species described in the world. They are known by your economical importance as wood curses and of other cellulose materials. The present work had the objective to evaluate the resistance of the wood of four forest species, very used in the urban arborization, to the attack of $C$. gestroi. The wood used for the accomplishment of the experimental were collected at the campus of the Rural Federal University of Rio de Janeiro. It was used, for the rehearsal, a masonry camera, where termites of the species C. gestroi happened naturally. Samples of the wood, measuring 6 to 8 $\mathrm{cm}$ of diameter and $5 \mathrm{~cm}$ of height were willing in five repetitions in the five blocks, inside of the same. After thirty days the samples were removed of the structure, being analyzed soon after. It was found a total of 220 insects. The species that more it suffered attack it was aquatica P. (46) and the one that fewer suffered attack was I. marginata (0). The I. marginata species is indicated for areas where the occurrence of termites is high, P. aquatic is not already indicated for infested areas. The density is not a factor that checks resistance to the termites, being attributed to the concentration of extractive toxicant, that function
\end{abstract}

Key-words: wood, durability, termites 


\section{INTRODUÇÃO}

Os cupins são insetos sociais da ordem Isoptera, que contêm cerca de 2750 espécies descritas no mundo. Mais conhecidos por sua importância econômica como pragas de madeira e de outros materiais celulósicos, os cupins também têm atraído a atenção de muitos cientistas devido ao seu singular sistema social. Além de provocar considerável dano econômico em áreas urbanas e regiões tropicais, exercendo papel essencial nos processos de decomposição e ciclagem de nutrientes (Constatantino, 1999).

Com a proibição dos organoclorados, no combate aos insetos, entre eles os térmitas, surgiu a necessidade de buscar-se alternativas ao seu controle, esse fato fez surgir novas moléculas inseticidas. Outra opção é encontrar madeiras naturalmente resistentes a tais organismos. Segundo Oliveira et al. (1986) dependendo da espécie, apenas um composto químico é o responsável pela resistência, enquanto em outras, vários componentes atuam de modo sinérgico, para conferir à madeira a sua durabilidade natural.

De modo geral são duas as espécies de cupins xilófagos causadores de prejuízos e presentes nas construções da área urbana da região sudeste do Brasil: Coptotermes gestroi (Isoptera: Rhinotermitidae), conhecido como cupim-subterrâneo e considerado a principal praga da região sudeste do Brasil e Cryptotermes brevis (Isoptera: Kalotermitidae), conhecido como cupim-de-madeira seca, cosmopolita e a segunda pior praga do sudeste brasileiro (Zorzenon \& Potenza, 1998).

De acordo com as informações geradas pelo Laboratório de Entomologia do I.P.T, os problemas diagnosticados nas edificações tratam-se, na maioria dos casos, de infestações por C. gestroi, espécie de cupim originária do sudeste da Ásia, que se adaptou muito bem às condições urbanas do Brasil, principalmente dos grandes centros urbanos como São Paulo e Rio de Janeiro.

Segundo Fontes (1998), Henderson et al. (1995) e Osbrink et al. (1999) além das edificações, observa-se também uma grande infestação de árvores por cupins-subterrâneos, que, pela dispersão subterrânea ou pela revoada, época do acasalamento, propaga o ataque termítico às edificações. As árvores constituem um foco para reinfestação de edificações tratadas, embora o inverso também possa ocorrer (Fontes, 1998). Segundo o mesmo autor, estes cupins são responsáveis por grandes prejuízos à arborização urbana, e as árvores constituem um abrigo para estes insetos. 
Relatos de árvores comuns à cidade de São Paulo, como a Sibipiruna, Jacarandámimoso, Quaresmeira, Acácia, Ipê, Paineira, Tipuana e outras, podem ser infestadas por cupins, o que pode acarretar sua morte.

Segundo Amaral (2002), no Brasil, não existem publicações referentes aos prejuízos econômicos causados pelos cupins xilófagos à arborização urbana. Segundo o mesmo autor este desconhecimento coloca em risco a população, uma vez que as árvores atacadas pelos cupins tornam-se mais sujeitas à quedas, principalmente durante e após temporais e ventos fortes, prejudicando a integridade de pessoas, animais, veículos e edificações, além disso, estas árvores podem ocasionar a infestação de edificações e prédios históricos e servirem de abrigo para estes insetos.

O objetivo deste trabalho foi avaliar a resistência da madeira de Clitoria fairchildiana .R.A. Howard "sombreiro" (Fabaceae), Pachira aquática Aubl. "Monguba" (Bombacaceae), Inga marginata Wild. "Ingá" (Mimosaceae) e Pseudosamanea guachapele (Kuntz) Harms "samanea" (Mimosaceae), à C. gestroi, essências muito utilizadas na arborização urbana do estado do Rio de Janeiro. Os dados de resistência natural da madeira, aos térmitas, podem servir de base para indicar ou não à utilização dessas árvores, em áreas de grande incidência de térmitas.

\section{MATERIAIS E MÉTODOS}

A madeira utilizada para a realização do experimento foi coletada no Instituto de Florestas do campus da Universidade Federal Rural do Rio de Janeiro, sendo cinco espécies arbóreas: C. fairchildiana, P. aquática, I. marginata e P. guachapele.

Foi utilizada, para o ensaio, uma câmara de alvenaria, onde térmitas da espécie $C$. gestroi ocorriam naturalmente. Cartões de papelão foram colocados, antes do ensaio, no piso do ambiente, com o objetivo de uniformizar a ocorrência dos térmitas dentro da estrutura conforme orientações de Trevisan \& Carvalho (2005). Logo após, amostras das madeiras, medindo 6 a $8 \mathrm{~cm}$ de diâmetro e $5 \mathrm{~cm}$ de altura foram dispostas em cinco repetições nos cinco blocos, dentro da mesma, que foi devidamente fechada, para que influências externas não atuassem no ensaio, como a luminosidade.

Após trinta dias as amostras foram retiradas da estrutura, em seguida, análises foram realizadas com o intuito de averiguar a freqüência dos térmitas nas mesmas. Os corpos de prova foram individualizadas em caixa tipo Gerbox forradas com papel cartão, tendo como intuito a atração dos xilófagos a este, pois não seria viável danificar as amostras, podendo comprometer a contagem dos insetos. A contagem dos insetos foi realizada em intervalos de 
sete dias, perfazendo um total de três, até que os mesmos não ocorressem mais na caixa. $O$ número de insetos presentes, em cada corpo de prova, foi registrado em tabela.

\section{RESULTADOS E DISCUSSÃO}

Foi encontrado um total de 220 insetos. O percentual de ocorrência dos térmitas, nas amostras, foi: P. aquatica (46) seguida de P. guachapele (34), C. fairchildiana (20) e $I$. marginata (0) (Tabela1). É importante destacar que a densidade não é o único fator que confere resistência, aos térmitas, a madeira. Segundo Barbosa et al. (2003), a alta resistência de algumas espécies madeireiras vem sendo explicada com base nas propriedades de seus componentes químicos, pois é consenso que existe uma estreita relação entre o teor de extrativos e a durabilidade natural da madeira, portanto o que atribuiu a resistência do Ingá, à ocorrência de térmitas, pode não ter sido a sua maior densidade e sim uma possível presença de extrativos tóxicos que inibiram o ataque. Os resultados obtidos nesta pesquisa corroboram com esta afirmativa, pois foi registrado uma maior intensidade de ataque na madeira de Monguba comparada com Samanea a qual apresenta uma densidade inferior.

Tabela 1-Percentagem de térmitas encontradas nas amostras da madeira das quatro essências arbóreas durante 30 dias de exposição ao ataque de C. gestroi.

\begin{tabular}{lc}
\hline \multicolumn{1}{c}{ Espécie } & Percentagem (\%) \\
\hline Pachira aquática & 46 \\
\hline Pseudosamanea guachapele & 34 \\
\hline Clitoria fairchildiana & 20 \\
\hline Inga marginata & 0 \\
\hline Total & 100 \\
\hline
\end{tabular}

O presente trabalho vem corroborar o estudo feito por Trevisan \& Carvalho (2005), que ao estudar a resistência natural da madeira de quatro essências arbóreas a C. gestroi, observou que a densidade não inibe o ataque a diferentes espécies, já que, entre as estudadas a madeira que obteve a maior intensidade de ataque foi justamente a que possuía a segunda maior densidade, Lophantera lactescens Ducke "lanterneira" (Malpighiaceae), enquanto que a menos atacada foi a que possuía menor densidade, Melia azedarach L. "Cinamomo" (Meliaceae), discordando de Bustamante \& Martius (1998), que ao estudarem a preferência 
alimentar de térmitas xilófagas, em laboratório, afirmam que a madeira de baixa densidade foi geralmente preferida.

Relativo à avaliação de resistência da madeira a térmitas, o principal protocolo utilizado pelos pesquisadores brasileiros é a norma internacional ASTM D-3345. Críticas a essa metodologia são feitas por diversos pesquisadores, uma vez que essa técnica não leva em consideração a biologia e a ecologia dos térmitas, pois, amostras dos insetos são obtidas em colônias, naturais ou de laboratório, e colocadas em vidros com areia e a madeira a ser avaliada, criando um ambiente artificial. Faz-se necessário novos protocolos que contemplem, essa avaliação, de maneira mais natural. Trevisan e Carvalho (2005) sugerem uma avaliação que leva em consideração a biologia e a ecologia dos insetos, sendo a metodologia utilizada neste experimental.

\section{CONCLUSÕES}

- A madeira que apresentou maior intensidade de ataque foi a Monguba, não sendo recomendado o plantio em áreas infestadas por térmitas.

- A madeira de Ingá não apresentou ataque dos térmitas, sendo seu uso indicado em áreas de ocorrência dos mesmos.

- A densidade da madeira não é o principal fator que confira resistência à mesma, podendo ser este a presença de extrativos tóxicos intrínsecos a cada espécie.

- Novos estudos relativos a extração química, dos compostos de cada madeira, devem ser instaurados, para avaliarem a ação tóxica aos agentes xilófagos.

\section{REFERÊNCIAS BIBLIOGRAFICAS}

AMARAL, R. D. A. M. Diagnóstico da ocorrência de cupins xilófagos em árvores urbanas no bairro de Higienópolis, na cidade de São Paulo. Piracicaba: [s. n.] 88 f. Dissertação (Mestrado em Recursos Florestais) Escola Superior de Agricultura "Luís de Queiroz", Universidade de São Paulo, 2002. 
BARBosA, A. P., MORAIS, J. W., SOARES, E. B., NASCIMENTO, C, S., JESUS, M, A. Efeito Tóxico de Componentes Químicos de Madeiras da Amazônia Com Relação a Térmitas. CD-ROM $8^{\circ}$ Congresso Florestal Brasileiro, 2003.

BUSTAMANTE, N. C. R., MATIUS, C. Nutritional preferences of wood-feeding térmites inhabiting floodplain forests of the amazon river, Brazil. Acta amazonica v. 28(3) p. 301307, 1998.

CONSTANTINO, R., Chave ilustrada para identificação dos gêneros de cupins (Insecta: Isoptera) que ocorrem no Brasil. Papéis avulsos de Zoologia, São Paulo, n. 40(25), p.387448, 1999.

FONTES, L.R. Considerações sobre a complexidade da interação entre o cupim subterrâneo, Coptotermes havilandi, e a arborização no ambiente urbano. In: FONTES, L.R.; BERTI FILHO, E. Cupins: o desafio do conhecimento. Piracicaba: FEALQ, 1998. p.109-124.

HANDERSON, G.; SHARPE, K.; FELIX, J. Sulfluramid baiting of termite infested trees in New Orleans: a preliminary report. Banton Rouge: Louisiana State University Agricultural Center, Departament of Entomology. 1995.

OliVEIRA, A.M.F., LELIS, A. T., LEPAGE, E. S., CARBALLERA LOPEZ, G .A., OLIVEIRA, L. C. S., CANEDO, M. D., MILANO, S. Agentes destruidores da madeira. In: LEPAGE, E. S. (Coord.) Manual de preservação de madeiras. São Paulo: IPT, 1986. v.1 p. 99-279

OSBRINK, W.L.A.; WOODSON, W.D.; LAX, A.R. Population of formosan subterranean termite, Coptotermes formosanus (Isoptera: Rhinotermitidae), estabilished in living trees in New Orleans, Louisiana, U.S.A. In: INTERNATIONAL CONFERENCE ON URBAN PESTS, 3., Prague, 1999. Proceedings. Prague: Czech University of Agriculture Prague. 1999. P.341-345.

TREVISAN, H.; Carvalho, A, G. Resistência natural da madeira de quatro essências arbóreas a Coptotermes gestroi (Wasmann, 1896) (Isoptera: Rhinotermitidae), um modelo de ensaio para ataque natural. CD-ROM $3^{\circ}$ Congreso Forestal Argentino y Latinoamericano, (2005). 
ZORZENON, F.J.; POTENZA, M.R Cupins: pragas em áreas urbanas. São Paulo: IB, 1998. 40p. (Ib. Boletim Técnico, 10). 